\title{
POTENSI PENGOLAHAN HASIL PERIKANAN \\ DI KAMPUNG BEBALANG KABUPATEN KEPULAUAN SANGIHE
}

\author{
Fish Processing Potential \\ In Bebalang Village Sangihe Island Regency
}

\author{
Novalina Maya Sari Ansar'), Frans Gruber Ijong ${ }^{2)}$ \\ ${ }^{1}$ Dosen Program Studi Teknologi Pengolahan Hasil Laut, Politeknik Negeri Nusa Utara \\ ${ }^{2}$ Dosen Program Studi Teknologi Hasil Perikanan, Universitas Sam Ratulangi Manado \\ Email: Novalinaa41@gmail.com
}

\begin{abstract}
Abstrak: Kampung Bebalang merupakan sebuah pulau kecil dengan luas wilayah $68,7 \mathrm{KM}^{2}$ yang secara administrative merupakan bagian dari Kecamatan Manganitu Selatan Kabupaten Kepulauan Sangihe. Kampung Bebalang memiliki potensi perikanan yang cukup besar khususnya untuk golongan ikan pelagis. Potensi perikanan di Kampung Bebalang belum dimanfaatkan secara maksimal untuk peningkatan kesejahteraan masyarakat yang sebagian besar bermata pencaharian sebagai nelayan. Oleh karena itu perlu dilakukan penelitian yang bertujuan untuk dapat mengidentifikasi potensi sumber daya perikanan, penanganan pasca tangkap serta potensi usaha pengolahan hasil perikanan dalam rangka peningkatan kesejahteraan masyarakat. Metode yang digunakan adalah metode survey dan observasi lapangan serta dianalisis secara deskriptif. Hasil penelitian menunjukan mayoritas penduduk Kampung Bebalang bermata pencaharian sebagai nelayan dengan berbagai hasil tangkapan yakni ikan tongkol, ikan julung-julung, ikan terbang dan yang paling dominan yakni ikan layang. Pada umumnya ikan hasil tangkapan dipasarkan dalam bentuk ikan segar dan sebagian diolah menjadi ikan asin, ikan asap utuh dan ikan asap pinekuhe. Proses pengolahan ikan dilakukan dengan cara yang masih sederhana dan bersifat tradisional serta belum menerapkan prinsip sanitasi dan hygiene serta belum menerapkan teknologi pengolahan.
\end{abstract}

Kata kunci: Ikan, Bebalang, Nelayan, Pengolahan

\begin{abstract}
Bebalang village is a typically small island, covering an area of $68.7 \mathrm{~km} 2$ administratively is part of Manganitu Selatan District Sangihe Islands Regency. This village has a promising potential of pelagic fish, which has not been optimally used to improve the life of the people in the village who mainly work as fishermen. Therefore, this research aimed to identify fisheries potential in the village to improve their welfare. We applied survey and field observation methods and descriptive analysis. The results showed that the majority of people in Bebalang were fishermen mainly catching tuna mackerel, the halfbeak, flying fish and the most dominant one, scad fish. Generally, most of the catch was sold in form of fresh fish and others were salted, smoked as pinekuhe or other types of smoked fish. Fish product processing was conducted traditionally without sanitary and hygienic applications as well as fish processing technology support.
\end{abstract}

Keyword: Fish, fisheries, fish processing 


\section{PENDAHULUAN}

Berdasarkan luas wilayah 93,8\% dari Kabupaten Sangihe adalah wilayah lautan maka Kabupaten Kepulauan Sangihe menyimpan potensi perikanan yang cukup besar untuk dikembangkan. Adapun potensi perikanan khususnya ikan pelagis berdasarkan data Dinas Kelautan dan Perikanan Kabupaten Kepulauan Sangihe yakni sebesar 323.400 ton dan untuk potensi perikanan tangkap yakni 34.000 ton /tahun dengan tingkat pemanfaatan baru sekitar 25\% atau sekitar 8.505 ton.Produksi terbesar adalah jenis ikan Layang (Decapterus russelii) 4.109,3 ton, Cakalang (Katsuwonus pelamis) 1.486,55 ton, Tongkol krai (Auxisthazard) 856,3 ton, Madidihang (Thunnus albacares) 656,05 ton dan Tongkol como (Euthynnus affinis) 601,15 ton (DKP Sangihe, 2016).

Kampung Bebalang merupakan gugusan dari tiga Pulau yang terletak di bagian wilayah Kecamatan Manganitu Selatan Kabupaten Kepulauan Sangihe. Bebalang terdiri dari Pulau Bebalang dengan luas 60,1 Ha, Pulau Mandaku dengan luas 5,7 Ha dan Pulau Dakupang dengan luas 2,8 $\mathrm{Ha}$, luas wilayah keseluruhan 68,7 Km2 (RPJMDes 2020 Kampung Bebalang).

Sebagai pulau kecil, Kampung Bebalang memiliki potensi ikan pelagis yang cukup dominan seperti ikan terbang, ikan layang, ikan julung-julung dan ikan tongkol serta ikan demersal hal ini disebabkan karena terumbu karang di Pulau Bebalang masih sangat terjaga sebagai tempat hidup ikan.

Besarnya potensi perikanan di Kampung Bebalang berbanding terbalik dengan kehidupan sosial ekonomi masyarakat Kampung Bebalang yang menggantungkan hidupnya pada hasil laut. Hal ini dikarenakan masih kurangya pengetahuan masyarakat tentang penanganan dan pengolahan ikan yang baik.

Penelitian ini bertujuan untuk mengetahui potensi sumber daya perikanan, penanganan pasca tangkap serta potensi usaha pengolahan hasil perikanan dalam rangka peningkatan kesejahteraan masyarakat Kampung
Bebalang. Sehingga melalui penelitian ini dapat memberikan informasi terkait pengembangan teknologi pengolahan perikanan.

\section{METODE PENELITIAN}

\section{Lokasi dan Waktu Penelitian}

Lokasi penelitian adalah Kampung Bebalang yang merupakan wilayah Kecamatan Manganitu Selatan. Waktu penelitian selama 6 bulan yakni dari bulan Mei sampai bulan November 2020 .

\section{Jenis dan Sumber Data}

Data yang diperoleh yakni data primer yang didapat melalui wawancara secara langsung dan data sekunder melalui studi literature dan dokumnetasi.

\section{Teknik Pengumpulan Data}

Pengumpulan data diperoleh melalui observasi dengan melakukan pengamatan terhadap potensi sumberdaya perikanan khususnya penanganan dan pengolahan hasil perikanan serta melalui wawancara dengan perangkat Kampung Bebalang, nelayan tokoh masyarakat dan ibu-ibu kelompok pengolahan hasil perikanan.

\section{Analisa Data}

Data primer dan data sekunder yang didapat di lapangan kemudian diolah secara deskriptif.

\section{HASIL DAN PEMBAHASAN}

Kampung Bebalang merupakan gugusan dari tiga Pulau yang terletak di wilayah Kecamatan Manganitu Selatan Kabupaten Kepulauan Sangihe. Berdasarkan letak geografis Kampung Bebalang sebelah Utara berbatasan dengan Kampung Pulau Mahumu, sebelah selatan berbatasan dengan Laut Sulawesi, sebelah Timur berbatasan dengan Kampung Pulau Batunderang dan Sebelah Barat dengan Laut Sulawesi.

Kampung Bebalang terdiri dari empat lindongan yakni Lindongan 1, Lindongan 2, Lindongan 3 dan Lindongan 4 dengan pola pemukiman 3 lindongan terkumpul di daratan perkampungan yang memanjang 
dari timur ke barat, sedangkan 1 lindongan berada di pulau mendaku dan dakupang Kampung Bebalang terdiri dari Pulau Bebalang dengan luas 60,1 Ha, Pulau Mandaku dengan luas 5,7 Ha dan Pulau Dakupang dengan luas 2,8 Ha, luas wilayah keseluruhan 68,7 Km2 (RPJM 2020 Kampung Bebalang).

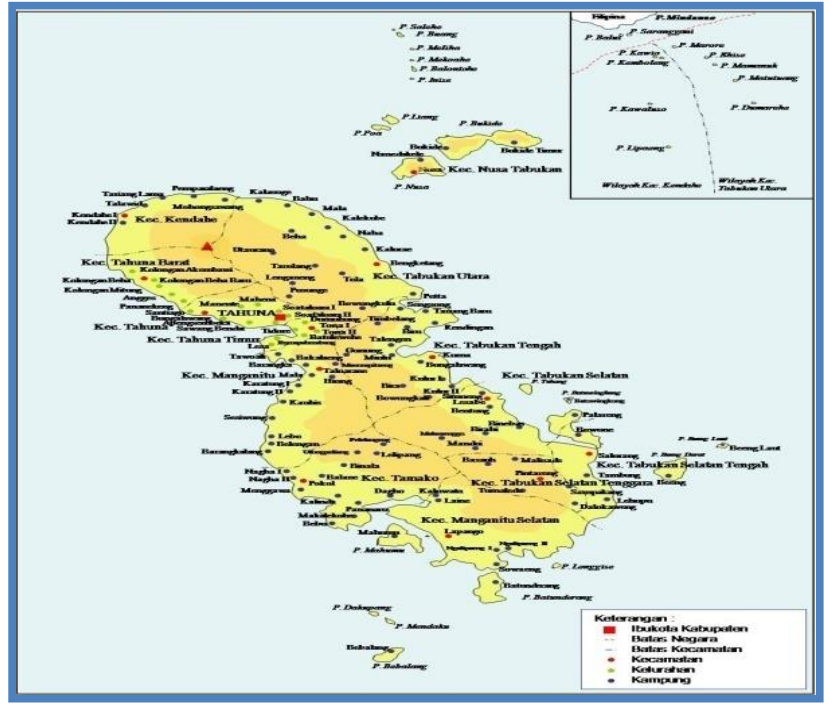

Gambar 1. Peta Kabupaten Kepulauan Sangihe (RPJMDes 2020 Kampung Bebalang)

Iklim yang ada di Kampung Bebalang, sebagaimana iklim yang ada di Indonesia pada umumnya yaitu beriklim Tropis dan mempunyai 2 musim yakni musim kemarau dan musim penghujan yang mempunyai pengaruh langsung kepada pola tanam dan para nelayan yang ada di Kampung Bebalang.

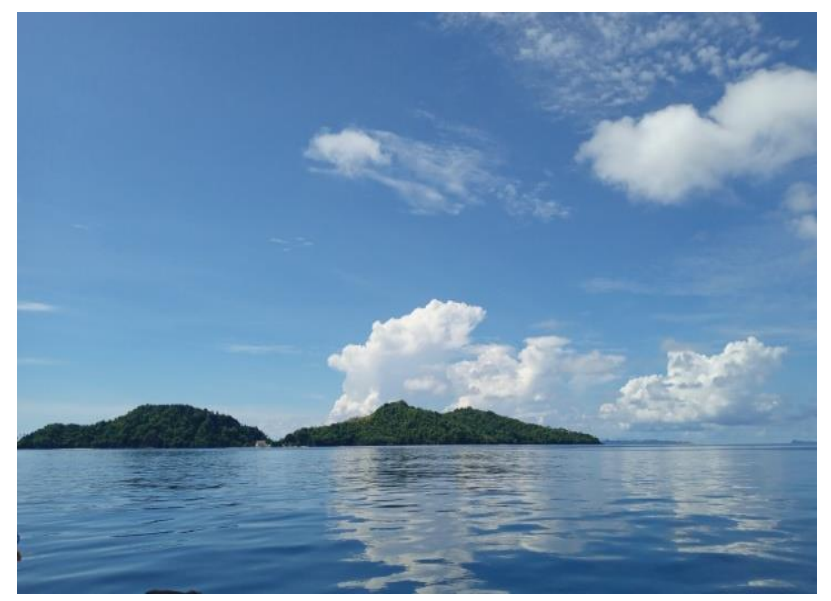

Gambar 2. Kampung Pulau Bebalang
Kampung Bebalang mempunyai jumlah penduduk 424 jiwa yang tersebar di 4 (empat) wilayah Lindongan. Dengan tingkat pendidikan yang beragam. Mata pencaharian penduduk di Kampung Bebalang sebagian besar adalah Nelayan dan Ibu Rumah Tangga dan hanya sebagian kecil yang berprofesi sebagai Pegawai Negeri Sipil Nelayan merupakan pekerjaan utama di Kampung Bebalang hal ini disebabkan karena $80 \%$ dari wilayah Kampung Bebalang merupakan lautan. Sehingga, untuk memenuhi kebutuhan sehari - hari, masyarakat setempat sangat bergantung pada hasil perikanan. Daftar mata pencaharian penduduk Kampung Bebalang dapat dilihat pada Tabel 1.

Tabel 1. Data Penduduk Kampung Bebalang Berdasarkan Mata Pencaharian

\begin{tabular}{|clc|}
\hline No & Jenis Mata Pencarian & Jumlah Jiwa \\
\hline 1 & Tani Penggarap & $\mathbf{0}$ \\
2 & Nelayan & $\mathbf{1 3 4}$ \\
3 & Tukang & $\mathbf{1 0}$ \\
4 & Usaha Kecil & $\mathbf{0}$ \\
5 & Swasta & $\mathbf{0}$ \\
6 & Peternak & $\mathbf{0}$ \\
7 & PNS & $\mathbf{3}$ \\
8 & Pensiunan & - \\
9 & Sopir dan Ojek & - \\
10 & Buruh Tani & $\mathbf{0}$ \\
11 & Buruh Tukang & $\mathbf{0}$ \\
12 & Buruh swasta & $\mathbf{0}$ \\
13 & Buruh Tidak Tetap & $\mathbf{0}$ \\
\hline
\end{tabular}

Sumber : RPJMDes Bebalang 2018-2024

Sebagai pulau kecil, Kampung Bebalang memiliki potensi ikan pelagis yang cukup dominan seperti ikan layang, ikan julung-julung dan ikan tongkol serta ikan demersal yang sangat besar karena disekitarnya banyak terdapat terumbu karang yang merupakan habitat yang baik untuk ikan. Berdasarkan data dari Dinas Kelautan dan Perikanan Kabupaten Kepulauan Sangihe, Kampung Bebalang memiliki potensi terumbu karang yang didominasi oleh jenis Acropora sp, Coral Massive dengan kondisi $95 \%$ baik sehingga merupakan habitat dari 
berbagai jenis ikan demersal yang memberi dampak pada tingginya produktifitas ikan karang yang bernilai ekonomis tinggi (Nikijuluw etal, 2013). Parameter Fisik di lokasi Kampung Bebalang perairannya memiliki suhu $28,7-29{ }^{\circ} \mathrm{C}$ dengan tingkat salinitas 31 ppm dengan $\mathrm{pH}$ 7.

Masyarakat Kampung Bebalang dahulunya menggunakan alat tangkap Seke untuk menangkap ikan di laut namun penggunaan alat tangkap tersebut sudah mulai hilang saat ini. Alat tangkap yang digunakan saat ini yakni mini purse seine atau dikenal dengan nama lokal soma pajeko dan longline(Widyaratmaya, 2013).

Hasil tangkapan nelayan sekali tangkap sebanyak dua puluh ribu ekor atau sekitar satu sampai dua ton. Hasil tangkapan biasanya dijual langsung di Pelabuhan Perikanan Dagho pada Perusahaan Umum Perikanan Indonesia (Perindo) dengan harga $1 \mathrm{Kg}$ ikan yakni delapan ribu rupiah. Pembagian hasil penjualan yakni sepertiga untuk yang punya kapal dan sisanya dibagi kepada nelayan yang ikut menangkap ikan. Kapal Penangkap Ikan dan Alat tangkap dapat dilihat pada Gambar 3.
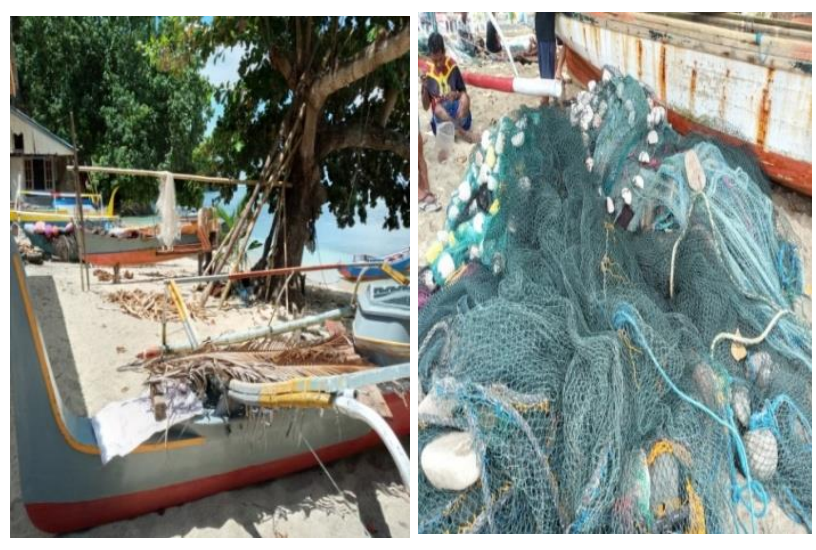

Gambar 3.Perahu Pumpboat dan Alat Tangkap Purse Seine (Soma Pajeko)

Produk perikanan khususnya ikan bersifat perishable food atau cepat mengalami pembusukan oleh karena itu membutuhkan proses penanganan yang cepat dan tepat (Afrianto dan Liviawaty, 2005). Sarana dan prasarana, tingkat ketrampilan dan pengetahuan nelayan dalam pengolahan ikan pasca panen merupakan faktor yang sangat menentukan kualitas dan standar mutu hasil tangkapan dan hasil olahan (Metusalach et al, 2014).Hasil tangkapan nelayan Kampung Bebalang yang diperoleh sebagian besar dipasarkan dalam bentuk ikan segar, dikonsumsi dan sebagian diolah menjadi ikan kering dan ikan asap dengan pengolahan yang masih sederhana dan tradisional.

Penanganan ikan saat ditangkap adalah faktor yang sangat penting dalam mempertahankan kualitas ikan sampai ikan diolah lebih lanjut. Perahu yang digunakan nelayan Kampung Bebalang dalam menangkap ikan tidak memiliki fasilitas palka sebagai penyimpanan persediaan es. Sehingga operasi penangkapan hanya berlaku sehari saja. Dimana nelayan akan turun melaut pada subuh dan akan kembali pada jam delapan pagi. Untuk selanjutnya hasil tangkapan dibawa ke Dagho atau Lapango untuk dijual dalam keadaan segar.

Karena tidak adanya fasilitas listrik PLN maka es yang biasa digunakan dalam penanganan ikan dibeli langsung dari Dagho. Nelayan Kampung Bebalang sudah memanfaatkan es untuk menyimpan ikan namun masih kurang pengetahuan tentang metode pengesan khususnya perbandingan antara es yang akan dipakai dengan jumlah ikan. Metode pengesan yang dilakukan yakni dengan metode bulking, ikan hanya ditimbun dengan es. Biasanya ikan hasil tangkap nelayan disimpan di box styrofoam atau coolbox kemudian di letakan di perahu atau di pinggir pantai kemudian ditutupi dengan terpal atau karung. Penanganan ikan yang dilakukan belum menerapkan prinsip sanitasi dan hygiene. Penanganan ikan hasil tangkapan dapat dilihat pada Gambar 4 di bawah ini. 

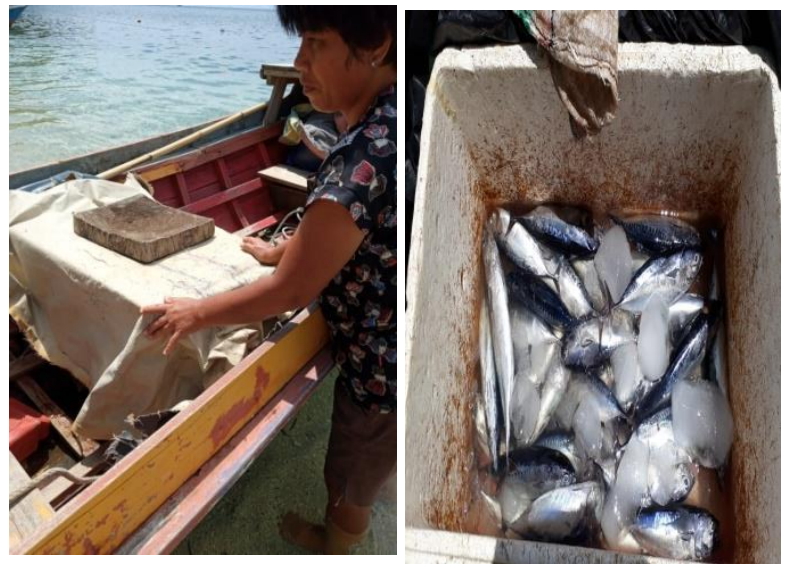

Gambar 4. Penanganan Ikan Menggunakan Styrofoaam

Ikan hasil tangkapan nelayan baik menggunakan mini purse seine atau longline biasanya diolah menjadi ikan asin dan ikan asap. Proses pengolahann yang dilakukan masih menggunakan teknik yang sederhana dan bersifat tradisional, serta kurang menerapkan prinsip sanitasi dan hygiene. Ikan yang biasa diolah menjadi ikan asin yakni ikan layang dan ikan julung-julung.

\section{a. Pengolahan Ikan Asin}

Setelah ikan ditangkap langsung diolah menjadi ikan asin dengan mengeluarkan isi perut,kemudian dicuci selanjutnya ikan ditiris dan setiap satu ekor ikan ditabur dengan menggunakan garam dapur. Garam yang digunakan tidak memakai takaran yang pasti hanya berdasarkan perkiraan. Setelah dua puluh menit ikan di tabur dengan garam, kemudian ikan dikeringkan di parapara yang terbuat dari kayu atau bambu atau biasanya di jemur di atas seng. Ikan dijemur selama tiga hari dari jam delapan pagi sampai jam 3 sore. Apabila cuaca hujan garam yang ditaburkan lebih banyak dari pada jumlah garam pada saat musim panas. Dan pada saat cuaca hujan ikan disimpan di dalam karung kemudian digantung supaya air yang ada dalam tubuh ikan meleleh. Ikan asin yang dihasilkan pada musim hujan kenampakannnya lebih putih karena garam yang digunakan cukup banyak dan rasanya lebih asin. Produk ikan asin yang dihasilkan biasanya dijual di Pasar Lapango, Pasar Towoe Tahuna dan Pasar Dagho. Penampakan ikan asin dapat dilihat pada Gambar 5.
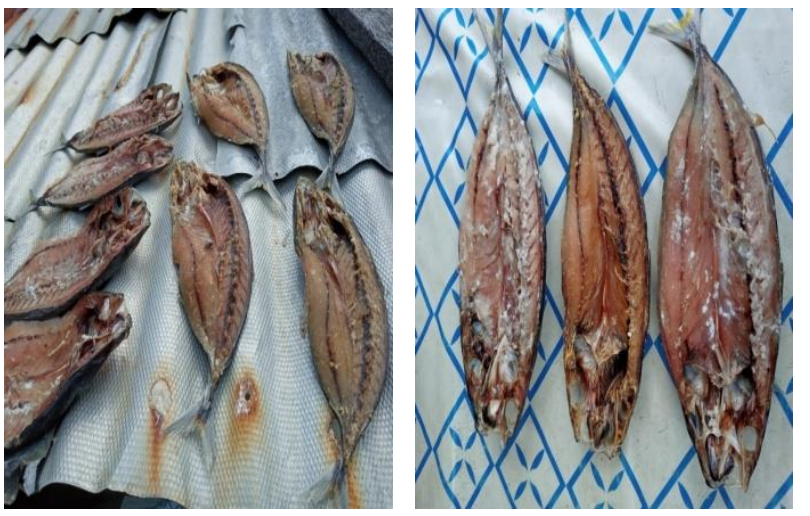

Gambar 5. Hasil Olahan Ikan Asin Masyarakat Kampung Bebalang

b. Pengolahan Ikan Asap

Pengolahan ikan asap di Kampung Bebalang ada dua macam yakni ikan asap pinekuhe dan ikan asap utuh yang bahasa local dikenal dengan nama Tinapa Talonde. Jenis ikan yang digunakan dalam pengolahan ikan asap yakni ikan layang yang diperoleh dari hasil tangkapan nelayan Kampung Bebalang. Setelah ikan di daratkan, ikan langsung diolah menjadi ikan asap. Proses Pengolahan ikan asap masih dilakukan dengan cara yang sederhana dengan menggunakan peralatan yang terbatas. Serta masih belum menerapkan proses sanitasi dan higiene.

Adapun pengolahan ikan asap yang dilakukan yakni ikan dibersihkan terlebih dahulu dengan mengeluarkan isi perut kemudian dicuci untuk menghilangkan darah dan kotoran yang menempel pada ikan. Kemudian ikan di tusuk dari bagian pipi sampe ekor menggunakan bambu sepanjang $50 \mathrm{~cm}$. Setelah itu ikan diletakan di atas para-para kayu dengan posisi menghadap ke bawah dengan maksud untuk meniriskan atau mengeluarkan air selama kurang lebih satu jam. Kemudian nyalakan api untuk proses selanjutnya. Selama proses pengasapan berlangsung biasanya menggunakan sak semen untuk menutup ikan yang sedang diasapi. Proses pengasapan ikan biasanya berlangsung selama tiga sampai empat jam. Selama proses pengasapan ikan dipindah- 
pindahkan sehingga masaknya merata. Ikan asap yang dibuat bisa tahan tiga sampai tujuh hari, dan bisa dipanaskan kembali di para-para. Ikan asap yang dihasilkan kemudian dijual di Pasar Tamako, Pasar Dagho, Pasar Lapango dan Pasar Laine.

Penampakan Ikan Asap dapat dilihat pada Gambar 6.
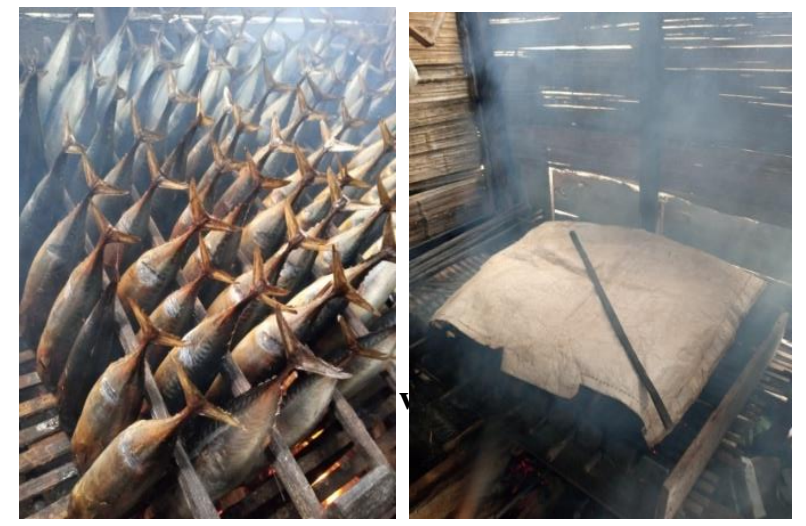

Gambar 6. Proses Pengolahan Ikan Asap Utuh (Tinapa Talonde)

Selain ikan asap utuh, di Kampung Bebalang juga terdapat pengolahan ikan asap pinekuhe. Ikan asap pinekuhe merupakan ikan asap yang memiliki bentuk yang unik yang merupakan produk ikan asap khas Kabupaten Kepulauan Sangihe (Karimela, 2020). Pengolahan ikan asap pinekuhe jenis ikan yang dipakai yakni ikan layang. Pengolahan ikan asap pinekuhe di Kampung Bebalang juga masih dilakukan dengan metode yang sederhana belum menerapkan teknologi pengolahan. Pemasaran ikan asap pinekuhe masih terbatas hanya dipasarkan di daerah sekitar Kampung Bebalang.
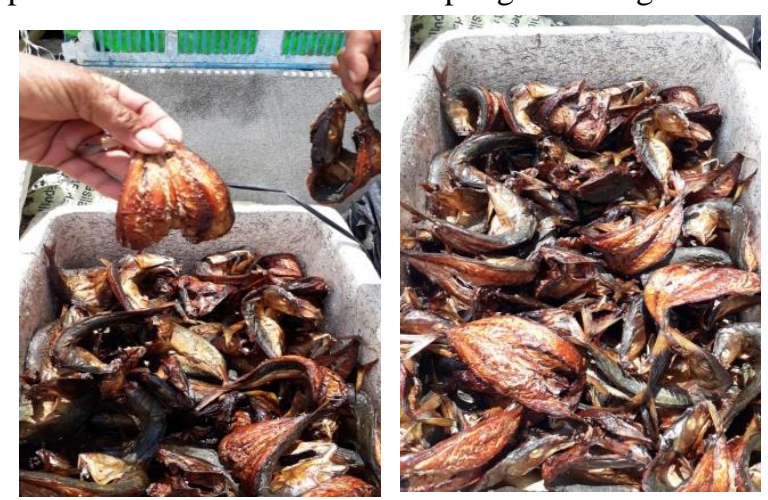

\section{KESIMPULAN}

Kampung Bebalang memiliki potensi sumberdaya perikanan yang cukup besar khususnya untuk ikan pelagis. Pengolahan hasil perikanan di Kampung Bebalang masih dilakukan dengan metode tradisional karena masih terbatas akan pengetahuan tentang pengolahan ikan dan masih kurangnya infrastruktur pendukung kegiatan pengolahan. Pengolahan ikan asin dan ikan asap di Kampung Bebalang belum menerapakn prinsip sanitasi dan hygiene.

\section{DAFTAR PUSTAKA}

Afrianto, E. dan Liviawaty, E. 2005. Pengawetan dan Pengolahan Ikan. Kanisius, Yogyakarta.

Dinas Kelautan dan Perikanan Kabupaten Kepulauan Sangihe. 2016. Statistik Perikanan Tangkap Kabupaten Kepulauan Sangihe. Tahuna.

Karimela E.J, 2020. Ikan Asap Pinekuhe. Pena Persada, Jawa Tengah.

Metusalach, Kasmiah, Fahrul, Ilham Jaya, 2013. Pengaruh Cara Penangkapan, Fasilitas Penanganan dan Cara Penanganan Ikan Terhadap Kualitas Ikan Yang Dihasilkan. Jurnal IPTEK Vo. 1 40-52

Nikijuluw V,PH, Adrianto L, Bengen DG, Sondita MF, Monintja D, 2013. CoralGovernance.IPBPress. Institut Pertanian Bogor. Bogor.

RPJMDES, 2020. Kampung Bebalang

Widyaratmaya, 2013. Seke dan Ikan Malalugis Di Desa Bebalang Kabupaten Kepulauan Sangihe, Provinsi Sulawesi Utara. Jurnal Sabda Vol. 8 Halaman 91-97.Bandung.

Gambar 8. Hasil Olahan Ikan Pinekuhe 